\title{
Corrupção e seleção por consequências: uma análise comportamental
}

\author{
Kester Carrara* \& Diego Mansano Fernandes \\ Universidade Estadual Paulista “Júlio de Mesquita Filho”, GEPEDEC - Grupo de Estudos e Pesquisas \\ em Delineamentos Culturais, Bauru, SP, Brasil.
}

\begin{abstract}
RESUMO - A corrupção é um fenômeno global. Sob os parâmetros teóricos e metodológicos da Análise Comportamental da Cultura, constitui nosso objetivo compor um panorama descritivo-explicativo da corrupção como prática cultural, mediante uma análise funcional de contingências implicadas em sua instalação e manutenção, particularmente no contexto brasileiro. Examinamos as origens etimológicas do termo corrupção, apresentamos um levantamento histórico sobre o tema nas ciências sociais e na Análise do Comportamento, delineamos o modelo de seleção por consequências e analisamos três situações hipotéticas de corrupção: (1) um exemplo de política institucional; (2) um exemplo de corporação privada em relação com o poder público; e (3) um exemplo de corrupção cotidiana. Concluímos apontando possíveis contribuições da Análise Comportamental da Cultura para prevenção e combate a práticas culturais corruptas.
\end{abstract}

PALAVRAS-CHAVE: corrupção, seleção por consequências, políticas públicas, análise comportamental da cultura

\section{Corruption and selection by consequences: a behavioral analysis}

\begin{abstract}
Corruption is a global phenomenon. Under the theoretical and methodological parameters of the Behavior Analysis of Culture, our goal is to compose a descriptive explanatory overview of corruption as a cultural practice, through a functional analysis of contingencies involved in its installation and maintenance, particularly in the Brazilian context. We examine the etymological origins of the term corruption, we present a historical survey on the topic in the social sciences and behavior analysis, we outline the consequences for model selection and analyze three hypothetical situations of corruption: (1) an example of institutional policy; (2) an example of private corporation in relation to the government; and (3) an example of everyday corruption. We conclude pointing to possible contributions of the Behavioral Analysis of Culture toward preventing and combating corrupt cultural practices.

KEYWORDS: corruption, selection by consequences, public policy, behavioral analysis of culture
\end{abstract}

A organização Transparency International, com o apoio de agentes locais espalhados em torno de 100 países, publica anualmente, desde 2001, o Corruption Perception Index (CPI) (Transparency International, 2015). "Baseado em opiniões especializadas ao redor do planeta (...)", o índice "mede os níveis percebidos de corrupção no setor público mundialmente" (Transparency International, 2015, p. 3).

A edição de 2015 contou com a avaliação de 168 países/territórios e foi feita por meio de uma escala de pontuação que varia de zero (muito corrupto) a 100 (muito limpo). Pontuações baixas indicam alta probabilidade de envolvimento de agentes públicos em diversas formas de corrupção. "Nenhum dos 168 países avaliados no índice de 2015 obteve uma pontuação perfeita, e dois terços pontuaram abaixo de 50 (...). Mais de seis bilhões de pessoas vivem em algum país com um sério problema de corrupção" (Transparency International, 2015, p. 3). A posição do Brasil no ranking desse ano foi a de número 76 entre os 168 avaliados, com 39 pontos, abaixo da média global e das Américas, com pontuação mais próxima da "metade mais corrupta" da escala (abaixo de 50 pontos). O Uruguai e o Chile são os mais bem colocados da América Latina, em $21^{\circ}$ e $23^{\circ}$ lugares do ranking mundial, com 74 e 70 pontos, respectivamente. Dados de levantamento feito pela agência em 2017 indicam que o Brasil ocupa agora não mais a posição 76 , mas a 96, o que sugere um declínio no ranking em vista de acontecimentos recentes, que serão abordados adiante (Transparency International, 2017).

Escolas mal equipadas, medicina despreparada e ineficaz bem como eleições decididas por meio do dinheiro são,

*E-mail: kester.carrara@uol.com.br 
segundo relatórios recentes da Transparency International (2014, 2015), algumas das consequências da corrupção no setor público. Realidade essa também frequente nas esferas nacional, estadual e municipal no Brasil, que, quase cotidianamente, vê seus noticiários inundados de notícias sobre o envolvimento de agentes do setor público em esquemas de corrupção.

Na história brasileira recente, acompanhamos diferentes episódios relacionados à corrupção no Brasil: o escândalo da suposta compra de votos no Congresso Nacional pelo PT, conhecido como "Mensalão"; corrupção envolvendo empresas estrangeiras e o governo do PSDB no estado de São Paulo nos contratos de licitação para compras de trens entre 1998 e 2008 para o transporte público, conhecido como "Tremsalão Tucano"; a Operação Lava Jato, ação da Polícia Federal para apurar a lavagem de dinheiro em seis estados e no Distrito Federal; bem como a série de episódios envolvendo a maior estatal brasileira e uma das maiores petrolíferas do mundo, a Petrobrás, como a compra da refinaria de petróleo de Pasadena, nos EUA, por 27 vezes o valor de mercado. O cenário alarmante é claro o bastante para que a corrupção seja entendida como prática cultural enraizada nas contingências sociais e políticas nacionais e internacionais. Isso a torna um objeto de estudo altamente relevante para as ciências do comportamento e, em particular, para a Análise Comportamental da Cultura.

O modelo explicativo adotado por essa disciplina é o desenvolvido por Skinner (1981/2007) a partir do pressuposto central de seleção pelas consequências, equivalente à noção de que o comportamento é função das consequências que produz nas relações com o ambiente em três condições mutuamente complementares de variação e seleção (filogenética, ontogenética e cultural). Nas palavras de Biglan (2003):

Em um nível teórico, a seleção por consequências proporciona um princípio transversal que identifica uma influência similar em diversos comportamentos e ações de grupos ou organizações. Em um nível prático, pode induzir investigadores, legisladores e profissionais a atentar para os efeitos das consequências aonde ainda não o fizemos anteriormente, ou ainda não tanto quanto poderíamos tê-lo feito. Em última análise, a busca profunda deste princípio pode nos levar a uma sociedade que reforça muito mais sistematicamente $\mathrm{e}$ generosamente comportamentos desejáveis e provê consequências mais eficazmente às práticas desejáveis de grupos e organizações. (p. 228-229)

Carrara (2015) propõe que a formulação de políticas públicas e a modulação de seus efeitos sobre os cidadãos podem ser amparadas pela lógica do modelo de seleção pelas consequências: "Assim, os planejamentos devem, também, ser compostos por elementos moduladores, ou seja, deve ser prevista uma instância de análise constante da eficácia dos reforçadores em vigor nas novas práticas" (p. 126). Biglan (2015) segue caminho semelhante e ilustra, valendo-se de uma série de experimentos e de programas governamentais em escala regional e nacional dos EUA, os benefícios que uma ciência do comportamento humano apoiada em evidências científicas pode trazer ao bem-estar geral, qualidade de vida e desenvolvimento das potencialidades humanas, no que chamou de Efeito Nutridor (nurture, frequentemente utilizado para fazer referência ao que é aprendido, em contraposição a nature, para características inatas).

Nesse sentido, são duas as estratégias prioritárias destinadas a responder aos objetivos deste estudo: (1) em função da longevidade, permanência e alta frequência relativa de ocorrência da corrupção em todas as nações, retratar aspectos fundamentais do percurso histórico de seu estudo nas ciências sociais e na Análise do Comportamento; (2) no contexto conceitual da Análise Comportamental da Cultura, mediante o modelo de seleção pelas consequências, proceder a uma análise funcional de possíveis contingências tipicamente implicadas na corrupção como prática cultural.

Essas estratégias viabilizam o objetivo geral do estudo, que é compor um panorama descritivo-explicativo da corrupção à luz do modelo comportamentalista radical. Tal tarefa é ilustrada por meio da análise funcional de três casos hipotéticos de corrupção, orientada para a identificação e descrição de variáveis contidas nas contingências sociais que provavelmente as mantêm. Esperamos que tal estratégia, ao se concretizar, possibilite a explicação de eventuais alternativas voltadas para atuação futura de pesquisadores e profissionais, voltada que será à prevenção dos malefícios sociais decorrentes das práticas corruptas. Insistimos em registrar previamente um alerta sobre estar completamente fora de qualquer cogitação a possibilidade de que uma análise comportamental da corrupção possa pretender-se completa mediante apenas um artigo como o presente, senão que se trata, unicamente, de inaugurar um necessário, amplo e vertical programa de pesquisas em Análise do Comportamento sobre tão relevante questão social.

Um segundo e não menos importante alerta é o de que o conhecimento científico produzido por tal programa de pesquisa só fará sentido se vier acompanhado de soluções no âmbito sistêmico e multidisciplinar. Assim sendo, um programa mais completo de pesquisas deve incluir uma análise de processos organizativos institucionais, em suas dimensões legais, políticas, econômicas e administrativas. 


\section{MÉTODO}

Este estudo tem natureza teórica, razão pela qual seus cuidados metodológicos contemplam, essencialmente, três dimensões: (1) o procedimento de seleção de textos para análise; (2) o procedimento de análise de tais textos; (3) o procedimento de elaboração e apresentação de situações em que se esclareçam contingências determinantes de variações do comportamento de corromper e corromper-se.

Em relação ao procedimento de seleção de textos, como o fenômeno da corrupção invade campos de conhecimento, teorias e disciplinas as mais variadas (Ciências Sociais, Economia, Filosofia, Antropologia, Psicologia), um critério de seleção de textos efetivamente vinculados aos objetivos do estudo foi empregado. Mais precisamente, foram selecionados artigos e outras publicações que, à primeira inspeção, sugeriam a possibilidade de identificação de relações entre os comportamentos de corromper e ser corrompido com as condições ambientais (majoritariamente as sociais), antecedentes ou consequentes, que controlam a ocorrência desses comportamentos. Além desse escopo, foram priorizados, no interior dessas publicações, aspectos que contribuíssem para: (a) a análise das variáveis relacionadas à descrição teórico-técnica do fenômeno; (b) a análise de variáveis relacionadas a possíveis estratégias de redução das práticas culturais de corrupção; (c) a análise e proposição de condições de replanejamento de práticas culturais compatíveis com a mediação teóricoepistemológica comportamentalista.

Em relação ao procedimento de análise, a partir da leitura dos textos selecionados, foram destacadas em um texto-resumo criado pelos autores para facilitar a sistematização, sob óptica comportamentalista, as asserções que contribuiriam para a instrumentalização de delineamentos culturais de controle e prevenção da corrupção.

Em relação ao procedimento de identificação de contingências determinantes da corrupção, a partir da elaboração teórica e da proposta metodológica expostas em Carrara et al. (2013), foram conjecturadas algumas possibilidades atuais de enfrentamento do problema da corrupção, nas acepções (b) e (c) do primeiro procedimento, especialmente centradas em novos procedimentos de pesquisa, estratégias de aplicação da legislação e reelaboração de políticas públicas norteadas pelo objetivo de mudança dos índices brasileiros encontrados no ranking da Transparency International. Ressalve-se ainda, a respeito de tais possibilidades, que quaisquer esforços são necessariamente limitados e preliminares, por razões que vão desde as mais singulares, como a necessária limitação de espaço dos artigos científicos para o desenvolvimento aprofundado de análises e propostas aplicadas, às mais complexas, como o número potencialmente infinito de variáveis envolvidas nas contingências em questão, além da necessidade de um trabalho que extrapola o campo conjectural.

\section{Breve Incursão Etimológica ao Termo Corrupção}

Não nos ilude a ideia de que com uma análise etimológica possamos descrever e compreender a corrupção como fenômeno comportamental. Para isso, necessitamos de um detalhamento do arranjo de contingências sob as quais corruptores e corruptíveis respondam. Todavia, uma brevíssima elucidação de origens e sentidos terminológicos pode auxiliar na extensa tarefa de identificar algumas características do tema estudado.

Conforme Faria (1962), a palavra latina corruptus significa deterioração, alteração, e de tais significados derivaram também corrupção e sedução. Para Cunha (1982), o termo corrupção remete ao verbo corromper, definido como "estragar, decompor, perverter, depravar" (p. 220), e deriva do latim corrumpere, conjugação de corrumpu. Para esse autor, (Cunha, 1982, p. 255), na lista de palavras que possuem alguma relação com o latim corrumpere encontram-se corrompente, corrompimento, corru(p)ção, corru(p)tela, corru(p)tibil, corru(p)tivel, corru(p)tivo, corru(p)to, corru(p)tor. Nem todas possuem o mesmo radical, mas todas apresentam significado atrelado ao verbo corromper, a depender do contexto histórico e da variação linguística em questão.

Note-se que a versão de Cunha (1982) para a etimologia da palavra corrupção remete ao verbo corromper, que, como verbo, pode ser especialmente interessante para uma análise comportamentalista do fenômeno. Um caminho promissor (embora indireto e mais lento do que ir diretamente à descrição das contingências implicadas) nesse sentido foi trilhado por Skinner (1989) em seu The origins of cognitive thought, por meio de uma análise etimológica de termos que designam processos mentais ou cognitivos para algumas abordagens psicológicas. Skinner notou que termos usuais no senso comum e em algumas abordagens psicológicas, como atenção, intenção ou propósito, mente e pensamento, entre outros, em termos de sua proposição histórica no desenrolar das teorias psicológicas e em termos de sua etimologia, "quase sempre começam como referências tanto a algum aspecto do comportamento quanto à circunstância na qual o comportamento ocorreu" (Skinner, 1989, p. 13).

As referências ao verbo corromper, no dicionário de Cunha (1982) e na primeira entrada do dicionário Aurélio (Ferreira, 2004), não autorizam a afirmação de que o mesmo aspecto observado por Skinner com termos cognitivos ocorre com a palavra corrupção, mas abrem a possibilidade de analisar o fenômeno pela mesma via. Em outras palavras, quando o dicionário remete o significado da palavra a um "verbo de ação", entramos no campo do comportamento e a análise da corrupção toma a forma de uma análise das condições nas quais alguém estraga, decompõe, perverte e deprava. Portanto, a análise de um fenômeno social crucial como a corrupção é, sobretudo, uma análise do comportamento corrupto, do corromper e do corromper-se. 


\section{Desenvolvimento Histórico dos Estudos sobre Corrupção}

Em documento por ocasião da Convenção interamericana contra a corrupção, a Controladoria Geral da União (CGU, 2007, p. 5) destacou a corrupção como um fenômeno que não é "característica exclusiva da cultura brasileira. Com a intensificação das relações internacionais e o fortalecimento da globalização, o problema atingiu escala mundial". O relatório de 2015 da Transparency International compartilha de posição semelhante: "não há sequer um país, em todo o mundo, que esteja livre de corrupção" (p. 3). Na esteira das duas organizações, a literatura é razoavelmente consensual em afirmar que, se por um lado a corrupção é um fenômeno que atinge várias sociedades, regimes e culturas, por outro, carrega uma gama de variações conceituais igualmente presentes nos diversos campos de estudo e disciplinas que a abordam, sendo afetadas por contextos históricos e culturais das diferentes tradições de pensamento que abordam o fenômeno (Mény \& de Souza, 2001).

Abramo (2005) delineia um breve panorama histórico do desenvolvimento dos estudos das ciências sociais no campo da corrupção, destacando Rose-Ackerman (1978) como precursora de uma abordagem crítica acerca do fenômeno e seu trabalho como um divisor de águas. Tais estudos, segundo Shleifer e Vishny (1993), focalizavam o comportamento corrupto dos agentes corruptores, como oficiais do governo e agentes da iniciativa privada cujo interesse era financiado por suborno e práticas semelhantes. Foi o momento em que se deixou de pensar a corrupção como elemento que azeitava o atravancado funcionamento burocrático da máquina estatal para destacar suas consequências negativas e seu impacto (maior do que se poderia supor) para a economia e organizações de modo geral.

Um interessante aspecto observado por Maciel (2005) é um suposto ponto em comum de todas as definições típicas, a ilegalidade. Ou seja, é comum e bastante óbvio que a corrupção seja tratada como algo ilegal. Todavia, sua proposta é a de que o fenômeno poderia ser estudado "como um comportamento racional dos agentes econômicos que agem em um mercado" (p. 16), eventualmente na ilegalidade, mas sem uma conotação moral necessariamente negativa.

Bobkova e Egbert (2013) reafirmam a vastidão de fenômenos e a miríade de situações que constituem o que se convencionou chamar de corrupção e, nesse sentido, que alguns artigos não darão conta de explicar o fenômeno, quanto mais propor soluções efetivas a ele, a despeito da literatura crescente já publicada e em produção. Os autores ainda salientam a importância de experimentos sobre corrupção e aspectos que estes permitem investigar, tais como influências culturais. Essa metodologia também permite a análise do papel do que chamam de efeito produzido por diferentes tipos de instruções sobre o comportamento corrupto, como as mais neutras ou as mais carregadas de sentido específico, bem como interligações entre o campo e o laboratório na pesquisa experimental. Salientam, ainda, a importância da pesquisa integrada entre diferentes disciplinas, trazendo uma perspectiva transdisciplinar para a resolução dos problemas sociais provenientes da corrupção.

Dessa mudança de perspectiva, portanto, emergiu um modo diferente de olhar para o fenômeno, e um número considerável de autores sinaliza com a pluralidade de disciplinas que passaram a abordar o fenômeno, o que, por sua, vez levou a uma pluralidade de definições de corrupção (Berninghaus et al., 2013; Bobkova \& Egbert, 2013; Maciel, 2005; Mény \& de Souza, 2001; Pellegrini, 2011; Shleifer \& Vishny, 1993). De acordo com Maciel (2005), as definições dependerão de qual disciplina lança seu olhar sobre o fenômeno e, com Bobkova e Egbert (2013), conclui-se que "a investigação sobre a corrupção produziu literatura abundante em disciplinas como Antropologia, Criminologia, Teoria do Desenvolvimento, Estudos Organizacionais, Ciência Política, Psicologia e Sociologia” (p. 346).

Diante de tal diversidade, parece importante examinar com prudência e critérios claros algumas dessas definições, com o objetivo de esclarecer suas principais diferenças e possíveis aproximações, e preparar o terreno para uma interpretação analítico-comportamental robusta e coerente com contingências sociais relevantes. Mény e de Souza (2001) distinguem duas categorias de definições: (1) definições contemporâneas das ciências sociais, subdivididas em três subcategorias: (1.1) definições centradas em cargos públicos, (1.2) definições centradas no mercado e (1.3) definições centradas no interesse público; e (2) operacionalizações.

Sobre as definições centradas em cargos públicos, os autores afirmam que os cientistas políticos, em sua maioria, adotam definições centradas nas práticas/comportamentos corruptos que violam os padrões formais/legais de regulação dos interesses públicos. A definição mais proeminente seria a de Nye (citado por Mény \& de Souza, 2001):

Corrupção é comportamento que desvia de deveres normais de um papel público por conta de interesses privados (...), pecuniários ou ganho de status; ou viola leis contrárias ao exercício de certos tipos de influência de interesses privados. Isso inclui tais comportamentos como suborno (...) nepotismo (...) e apropriação indevida... (p. 2824)

Segundo Mény e de Souza (2001), tal definição não é muito diferente das encontradas em códigos penais e que vêm atraindo criminologistas e cientistas políticos. Essas definições, além de estáveis e objetivas, poderiam facilitar a identificação e combate às práticas sociais e culturais corruptas, uma vez que dão visibilidade ao processo subjacente à constituição da corrupção. No entanto, apesar de sua clareza e objetividade, ainda denotam certa limitação de conceituações e definições, por estritas ou simplistas, pois as situações sociais nunca são delimitadas e circunstanciadas como nos textos legais-normativos, deixando muitos aspectos indefinidos ou inexplicados. 
Sobre definições centradas no mercado, os autores apontam que existem acadêmicos que, a partir das teorias econômicas, definem corrupção "em termos de troca de dinheiro por decisões políticas (ativa), que atores privados procuram adquirir (demanda), e que agentes públicos estão muito dispostos a vender (prover) evitando ser pegos (passiva)" (Mény \& de Souza, 2001, p. 2825). Tal definição é apoiada em transações como suborno, comissão ilícita, propinas previamente acordadas, entre outras, bem como nas chamadas teorias econômicas de escolha racional, nas quais são tomadas decisões pelos agentes envolvidos de modo a maximizar seus lucros ou ganhos e reduzir os prejuízos ou perdas, com o diferencial de tirarem proveito da máquina pública e manterem privilégios de posição. Para os autores, outro aspecto importante é a suposta negligência dessa perspectiva às questões morais envolvidas na tomada de decisões. Não fica claro em que medida as condições do meio em que vive o agente exercem um papel em sua escolha. Em campo parecido, há ainda a definição de "market(s) of corruption" (p. 2825), que leva em consideração trocas paralelas em mercados obscuros, como os chamados mercados negros.

Sobre definições centradas no interesse público, argumenta-se que cientistas políticos descontentes com as limitações das definições anteriormente apresentadas propuseram uma alternativa, segundo a qual "corrupção é um comportamento desviante ou prática caracterizada essencialmente pelo subjugo de interesses públicos por privados" (Mény \& de Souza, 2001, p. 2825). No entanto, Mény e de Souza (2001) apontam as dificuldades inerentes a um consenso sobre interesses públicos, por vezes carregados de valores típicos de uma moral pública que não parece encontrar sustentação à medida que se alteram, ao longo do tempo, contextos sociais e políticos. Logo, definições de corrupção que façam referência a tais questões talvez pouco ajudem em um empreendimento de construção de uma caracterização científica e pragmática do que seja corrupção. Nessa perspectiva, tais definições são insuficientes para os propósitos de um ensaio conceitual como este, especialmente interessado em descrever como (de um ponto de vista comportamentalista) ocorre o fenômeno, em contrapartida a identificar o que ele é ou quando e em que casos ou situações pode, por exemplo, ser criminalmente enquadrado.

Sobre as operacionalizações para a realização de pesquisas empíricas a respeito do fenômeno da corrupção, são necessários critérios claros que indiquem aquilo que pode vir a ser ou não corrupção, e tais medidas não são muito simples de delimitar e adotar, uma vez que as definições apresentadas comumente na literatura de várias disciplinas resvalam em conceitos a um só tempo legais, culturais, situacionais e contextuais, sendo, portanto, de difícil especificação. Haveria uma "nebulosidade" na corrupção que dificultaria o estabelecimento de padrões de análise e definição, que precisam ser contornados para que se tornem possíveis reformas sociais que impliquem redução da corrupção (Mény \& de Souza, 2001). Nessa mesma linha, Cameron, Chaudhuri, Erkal e Gangadharan (2008) apresentam uma definição própria, com a finalidade de colher dados experimentais entre diferentes países e analisá-los quanto às suas peculiaridades: "Em nosso artigo, interpretamos corrupção como uma situação em que duas pessoas podem agir para aumentar seu próprio benefício à custa de uma terceira pessoa, a vítima" (p. 2). Ainda que o esforço de operacionalização seja essencial em vários sentidos (no nosso caso, com vistas a uma análise comportamental), tal proposta não parece avançar o bastante no que diz respeito ao como se dá o comportamento corrupto (o que faz cada um dos "atores" na situação descrita). O resultado é que uma gama ampla de ações pode ser considerada (equivocadamente) corrupção, como um simples furto.

Preocupação semelhante pode ser observada nas instâncias institucionais e jurídicas, sendo o combate a comportamentos corruptos (ou genericamente rotulados como corrupção) a principal tarefa. Sem que se ocupe de definições funcionais ou operacionais, o Código Penal brasileiro (Brasil, 1940) menciona uma série de atos considerados ilegais e que são passíveis de punição, especificamente no caso de crimes praticados por funcionários públicos contra a administração em geral. Alguns dos que poderiam caracterizar corrupção seriam: Peculato - Art. 312 e 313, descrito como "Apropriar-se o funcionário público de dinheiro, valor ou qualquer outro bem móvel, público ou particular, de que tem a posse em razão do cargo, ou desviá-lo, em proveito próprio ou alheio"; Concussão-Art. 316, descrito como "Exigir, para si ou para outrem, direta ou indiretamente, ainda que fora da função ou antes de assumi-la, mas em razão dela, vantagem indevida"; Corrupção Passiva - Art. 317, descrito como "Solicitar ou receber, para si ou para outrem, direta ou indiretamente, ainda que fora da função ou antes de assumi-la, mas em razão dela, vantagem indevida, ou aceitar promessa de tal vantagem"; e Prevaricação - Art. 319, ou "Retardar ou deixar de praticar, indevidamente, ato de ofício, ou praticá-lo contra disposição expressa de lei, para satisfazer interesse ou sentimento pessoal".

Uma ressalva é necessária a respeito dos indicativos do Código Penal (Brasil, 1940). Acreditamos que a complexidade e a multiplicidade das condições de vida da sociedade brasileira tornam inviável, ou ao menos muito difícil, que os parâmetros legais possam acompanhar, ao longo do tempo, a dinâmica de mudanças no controle ético exercido pelos diferentes grupamentos sociais. Nesse sentido, uma identificação clara do que é ou não é corrupção adquire contornos nebulosos. Algumas formas de "jeitinho brasileiro" podem ser ilegais em um contexto e legais em outro e, ainda, práticas podem ser consideradas éticas e ilegais, ou legais e antiéticas, a depender do arranjo de contingências dos contextos específicos. 


\section{Corrupção e Análise do Comportamento}

Até meados de 2016 (época da elaboração deste artigo), eram poucos os estudos disponíveis voltados para uma análise comportamental da corrupção. Alguns possíveis exemplos de estudos que se aproximaram da tarefa ou desenvolveram estudo correlato são Fernandes, Perallis, Pezzato (2015), Goldstein e Pennypacker (1998), Lamal e Greenspoon (1992) e Agbota, Sandaker e Ree (2015). O primeiro se detém em análises funcionais do fenômeno internacionalmente conhecido como "jeitinho brasileiro", explorado em termos da dimensão ética controversa de suas consequências sociais. $\mathrm{O}$ segundo analisa contingências políticas que caracterizam a transição de um candidato a um cargo público à condição de político criminoso que, uma vez eleito, se perde em meio aos conluios típicos do sistema político corrupto que o cerca. $O$ terceiro constitui exame de metacontingências eleitorais no congresso estadunidense, comparando, de um lado, a percepção de eleitores a respeito de determinados candidatos e, de outro, os votos válidos, em busca das variáveis que controlam o comportamento verbal em relação aos políticos e também o comportamento de votar. O quarto constitui uma análise comportamental do uso de metáforas e eufemismos como retrato do engajamento em práticas corruptas em Gana, especificamente subornos.

\section{Uma Análise Comportamental de Práticas Culturais Corruptas}

Uma análise comportamental da corrupção como fenômeno social requer, em primeiro lugar, um detalhamento dos aspectos pelos quais ela difere de outras análises, como as sociológicas, antropológicas e mesmo as chamadas "psicológicas". Em outras palavras, é preciso explicitar o que significa esse comportamental e algumas de suas implicações.

De forma análoga à seleção natural darwiniana conjecturada como proposta explicativa do processo evolutivo, o ambiente, desta vez mediante o conceito de contingência de reforçamento, ocupa um lugar central na explicação de processos comportamentais (Skinner, 1969/1984). B. F. Skinner detalhou ao longo de sua obra muitos aspectos daquilo que mais adiante em sua carreira tratou de sistematizar, no âmbito do Comportamentalismo Radical e da Análise do Comportamento: os níveis de seleção do comportamento pelas consequências. Esses níveis de variação e seleção, cuja descrição pormenorizada é dispensável em função de serem amplamente conhecidos na Análise do Comportamento, consistem em (1) filogênese, ou história de desenvolvimento da espécie; (2) ontogênese, ou história de desenvolvimento de um indivíduo no transcurso de sua existência; e (3) cultura, ou história de desenvolvimento de contingências sociais entrelaçadas que caracterizam um ambiente social complexo (Skinner, 1981/2007).
É importante frisar que uma análise da corrupção como classes de comportamentos operantes implica, necessariamente, concentrar esforços em formas de organização social controladas por consequências específicas. Skinner (1981/2007) argumenta que a emergência do comportamento verbal permitiu à espécie alcançar uma complexidade crescente na forma como organiza seus ambientes. Em outros termos, permanecemos agora no âmbito da cultura, referente à seleção por consequências no desenvolvimento, manutenção e alterações de conjuntos de contingências sociais ou culturais (Fernandes, Carrara, \& Zilio, 2017). Estamos, nesse sentido, sempre falando em cultura de um ponto de vista comportamentalista e, consequentemente, tratamos a corrupção como um conjunto de ações ou comportamentos que são modelados ou mantidos por arranjos complexos de contingências sociais, organizados por grupos ou agências de controle em contextos específicos.

Diante desse cenário, consideramos relevante deixar de tratar a corrupção como um substantivo, no sentido de uma entidade ou "coisa", "defeito moral", "estrutura mental ou de personalidade", "traço ou tendência imanente" ou "racionalidade" que causa o comportamento das pessoas e traz prejuízos sociais. Passamos a localizá-la, como sugere (ainda que indiretamente) parte da literatura até aqui examinada, a origem etimológica e os significados históricos da palavra, no comportar-se de maneira corrupta em diversos contextos sociais. Mais precisamente, especificar situações antecedentes comuns a esse comportamento, algumas de suas variantes e os tipos de consequências aí implicados, elucidando os processos comportamentais que mantêm tais práticas em alta frequência, como ilustram dados apresentados pela Transparency International e considerados pela CGU.

Para responder a tais questões empregaremos, preliminarmente, o artifício de uma análise funcional de algumas situações práticas aqui bastante simplificadas de comportamentos corruptos, entre elas (1) um exemplo da política institucional; (2) um exemplo de uma corporação privada em relação com o poder público; e (3) um exemplo de corrupção do cidadão em seu dia a dia. As diferentes situações caracterizam distintas esferas da corrupção como fenômeno cultural amplo e complexo e explicitam, do ponto de vista funcional, relações entre organismo e ambiente como quaisquer outras. Destacamos que a escolha das três situações em questão não tem por premissa ou objetivo sugerir alguma equivalência ética entre elas. A própria divisão entre relações que se dão num âmbito público e num âmbito privado carrega implicações que nos impedem de proceder a tal julgamento.

Em relação ao campo da política institucional, uma situação bastante típica é a troca de favores por meios obscuros, frequentemente envolvendo dinheiro e desafiando os limites da legalidade. Como exemplo inicial hipotético, tomemos um governador que destina receitas do orçamento 
para setores específicos de acordo com seus interesses pessoais e partidários. O contexto amplo é o que se segue: o governador é eleito, possivelmente com uma margem de votos razoável em relação ao segundo colocado. Ao assumir (ou mesmo antes disso) o comando do governo do estado, começam as reuniões para definição de secretários, definição de prioridades e destinação de verbas. Quais as contingências envolvidas nos comportamentos de indicação de servidores e quais as contingências envolvidas na definição de prioridades de investimento público?

São comuns no noticiário jornalístico os casos em que, para conseguir apoio da maioria na Assembleia e de parcela suficiente dos partidos de "oposição" que garanta governabilidade, o governador adota a manobra de distribuir cargos de forma conveniente entre a base aliada do governo e a oposição. As condições que controlam suas indicações, portanto, já demonstram que as consequências principais em questão dizem respeito aos grupos do poder e dizem respeito à sustentação política do governo, bem como à real possibilidade de ter suas propostas levadas adiante pelos legisladores. A definição de prioridades de investimento público permanece sujeita aos mesmos tipos de interesses, ou seja, a sustentação do governo mediante o "agrado" da base aliada e da oposição com participação negociada no aparelho estatal. Negligenciadas, nesse exemplo, as demandas públicas concretas, caminhamos para o exemplo da corporação privada.

Embora seja uma prática comum em outros países, como nos EUA, a legislação eleitoral brasileira foi alterada em 2015 por meio de mudanças nas regras para o financiamento privado de campanha: pessoas físicas podem doar até $10 \%$ do rendimento bruto declarado em imposto de renda no ano anterior, e as pessoas jurídicas ou empresas estão proibidas de doar. No entanto, essa foi uma prática comum no país até então, e a relação simbiótica entre empreiteiras de grande porte e a república é fato corriqueiro nas investigações da Operação Lava Jato ${ }^{1}$. Corporações doam quantias vultosas de dinheiro para os candidatos de sua preferência, por vezes, mais de um. Após o período eleitoral, o processo brevemente descrito no exemplo anterior se inicia - mesmo no caso de reeleição, é comum uma "reforma" ministerial, ou na pasta de secretários estaduais e municipais - e entram em cena relações espúrias entre os serviços públicos, licitações e concessões, e empresariado financiador de campanha. Como se comportam os atores em questão: firmam contratos de natureza duvidosa e serviços de qualidade mais duvidosa ainda são práticas comuns; formam parcerias público-privadas coordenadas por profissionais de competência a conferir e, eventualmente,

1 Um grande empreiteiro teria ameaçado "derrubar a república" caso fosse preso, conforme informações disponíveis em: $<$ http://epoca. globo.com/tempo/noticia/2015/06/marcelo-odebrecht-ameaca-derrubarrepublica.html> de ficha policial extensa; protagonizam escândalos de lavagem de dinheiro e aparelhamento estatal nos noticiários. Entre algumas das consequências estão o aparelhamento do Estado pelos grupos no poder e pelo empresariado envolvido; a ausência de alternativas de punição efetivas, pois flagrantes são raríssimos e o custo de resposta de tais práticas punitivas acaba sendo baixíssimo a curto e médio prazo, principalmente quando comparado com o alto custo de resposta necessário (especialmente político) para manter o funcionamento da máquina pública dentro do rigor da lei, frequentemente burocrática. Os cidadãos, que esperam ter suas demandas atendidas, mas as têm, de fato, frustradas pelas consequências da corrupção e pela burocracia, também podem se engajar em algum tipo de atividade corrupta, o que nos leva ao exemplo de comportamento corrupto do cidadão.

Conforme esforço da campanha "O que você tem a ver com a corrupção?", iniciada no Ministério Público de Santa Catarina e atualmente conduzida pelo Conselho Nacional dos Procuradores-Gerais do MP dos Estados e da União (CNPG) e pela Associação Nacional dos Membros do Ministério Público (CONAMP) ${ }^{2}$, o cotidiano está envolto em inumeráveis tentativas de obter vantagem pessoal em detrimento dos interesses dos outros e do espaço público como um todo. Os modelos desse tipo de prática são históricos e se perpetuam nas diversas esferas sociais do país (e do mundo todo, em maior ou menor grau) - especialmente pelo modo como os políticos lidam com os recursos e espaços públicos sem consequências aversivas relevantes - e "jeitinhos" são uma característica observada em alta frequência na população brasileira.

A lógica central das práticas ilícitas implica contingências sociais cotidianas que envolvem o conceito de custo (no caso, baixo) de respostas corruptas, alta taxa de reforçadores positivos em curto prazo (lucro financeiro ou outras vantagens ilegais), bem como risco reduzido de punição a curto e médio prazo (sanções legais), conjunto esse de condições que acaba modelando e mantendo comportamentos corruptos. Seu rol de modalidades vai desde os mais aparentemente insignificantes, como a falsificação de carteirinhas de estudante para desconto de meia entrada no cinema e teatro, por exemplo, aos mais complexos, como o suborno e pagamento por favores e "jeitinhos" que driblem a fiscalização e as normas de licitações públicas.

Cabe registrar ainda que uma série de condições culturais também configura o contexto amplo para os exemplos de comportamento corrupto e corruptor, como a ausência de estruturas educacionais para formação de modelos "honestos e transparentes" de repertórios políticos, em trabalho educativo de desenvolvimento e instalação de

2 Recuperado de $<$ http://www.gnmp.com.br/publicacao/56/campanhanacional-o-que-voce-tem-a-ver-com-a-corrupcao $>$ e $<$ http://www.mprj. $\mathrm{mp}$.br/cidadao/projetos-e-campanhas/campanha-nacional-o-que-vocetem-a-ver-com-a-corrupcao> 


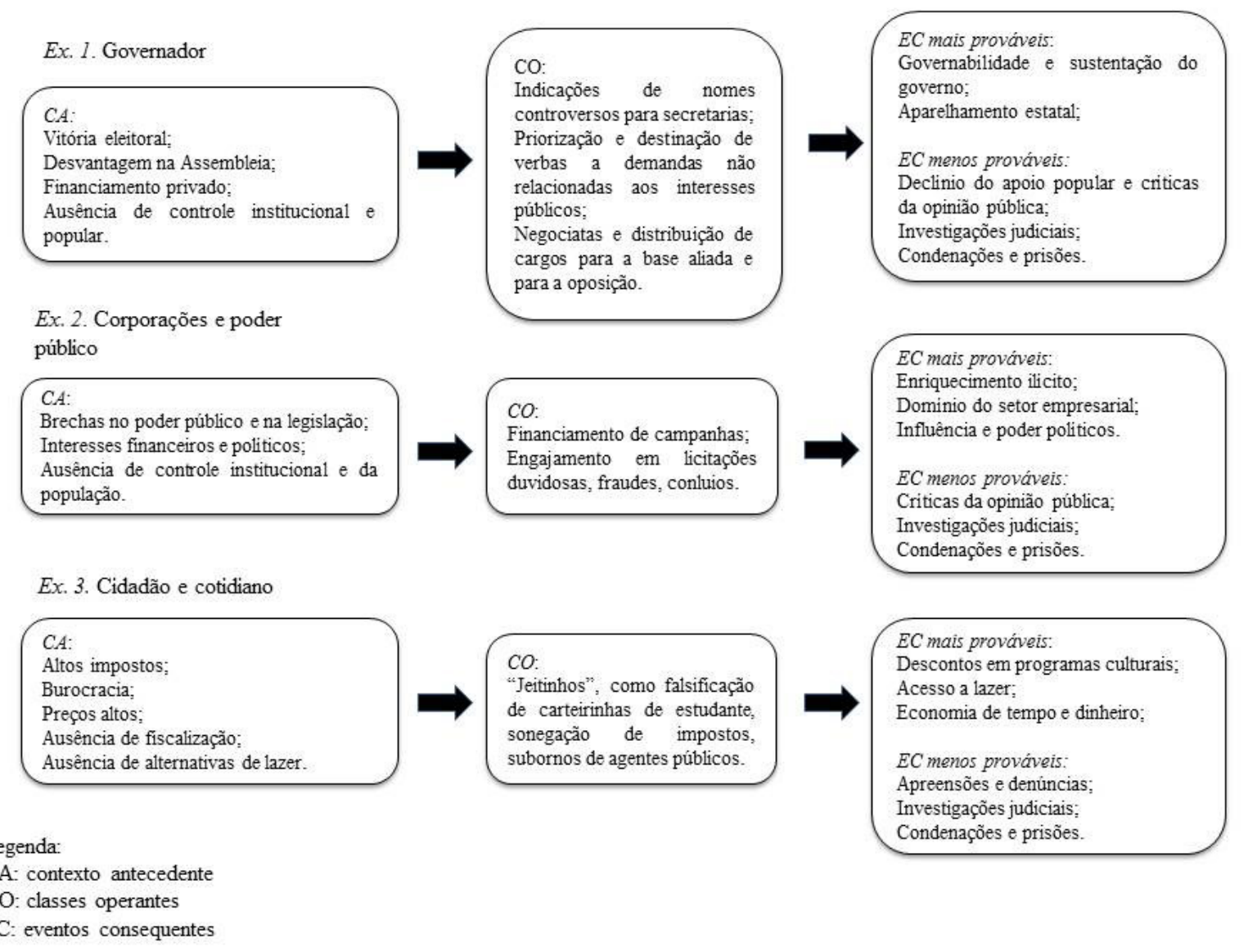

Figura 1. Contingências sociais em três casos de corrupção

comportamentos pró-sociais que se inicia na infância, em interlocução entre a comunidade e a escola Exemplos de estudos nessa direção podem ser encontrado em Carrara e Betetto (2009) e em Bolsoni-Silva et al. (2013).

A Figura 1 ilustra algumas das contingências mencionadas nas situações-exemplo já apontadas:

Até então procuramos deixar claro que a corrupção precisa e pode ser analisada em termos dos conjuntos de contingências sociais que constituem a cultura como um todo (Fernandes et al., 2017) e, mais especificamente, que modelam e mantêm comportamentos corruptos em várias esferas da sociedade, das quais mencionamos e analisamos brevemente exemplos bastante simplificados do setor público, das relações entre o setor público e o privado, bem como do cotidiano do cidadão comum. Evidentemente, há "tramas" bastante complexas no âmbito do poder público, envolvendo uma sequência de condicionantes para comportamentos individuais e práticas culturais de corromper e corromper-se, o que sugere, caso a caso, um exame acurado das contingências que mantêm a corrupção e, em contrapartida, aquelas que produziriam uma mudança nesse panorama.

Em linhas gerais, a despeito de recentes mudanças no cenário político brasileiro, relações de custo-benefício entre as respostas que caracterizam o comportamento corrupto e as consequências que produzem indicam que corromper-se e corromper "valem a pena", no sentido de que há pouca ou nenhuma consequência aversiva contingente nos âmbitos comunitário e legal ou jurídico e, quando há consequências legais, todo o processo judicial envolvido leva tempo e pode ser atenuado pelos recursos disponíveis pelos cargos públicos (prerrogativas de foro), poder econômico e advogados competentes. As relações são típicas do dilema consequências de curto-prazo versus consequências de longo-prazo: no caso de problemas sociais, o poluir, individualmente, não representa risco significativo visível para o ambiente. Da mesma maneira, fumar, por parte de uma única pessoa, não representa risco iminente para a saúde. Burlar a lei, corromper e corromper-se possibilitam eventuais consequências aversivas apenas no longo prazo, com raras punições efetivas no curto prazo. Diante desse cenário de corrupção sistêmica, o que pode fazer o analista comportamental da cultura para auxiliar na mudança do ciclo de disseminação da corrupção como prática cultural?

Em reflexão sobre temas importantes como bem-estar social e degradação do meio ambiente, Biglan (2016) argumentou pelo desenvolvimento de estratégias mais efetivas de predição e influência de fenômenos culturais, que teriam como suas prioridades "o desenvolvimento de uma ciência das práticas culturais que avalie experimentalmente 
estratégias para influenciar as práticas de organizações formais e governos" (p. 3). Para o pesquisador, são necessários o fortalecimento de estratégias de pesquisa empírica; fortalecimento de programas baseados em evidências que promovam mudanças palpáveis, com destaque para o desenvolvimento de repertórios prósociais; e fortalecimento de estratégias de convencimento e persuasão de diferentes agentes sociais (públicos e privados). Acrescentaríamos que essa "persuasão" consiste em consequenciação diferenciada e demanda medidas adicionais para mudanças necessárias de comportamento. Nesse sentido, consideramos que a atuação dos planejadores de práticas culturais poderia incluir medidas em torno dos seguintes eixos: (1) reversão do baixo custo de resposta dos repertórios corruptos e corruptores; (2) reconhecimento social de práticas que envolvam cooperação, transparência e solidariedade; (3) reforma política para radicalização da democracia.

Os eixos mencionados constituem um projeto amplo de mudança cultural, que tem como consequências desejadas a coibição do engajamento em práticas corruptas e corruptoras, o que seria uma medida redutora dos profundos danos à sociedade provocados por essas práticas. Conforme afirmam Araujo, Melo e Haydu (2015), é preciso adequar os dispositivos legais às contingências sociais em vigor, o que implicaria atualizar e reavaliar constantemente as leis e possibilidades de cumprimento conforme o sinal dos tempos. É preciso fortalecer repertórios positivos e prósociais, através de programas de educação ético-moral nas esferas pública e privada desde os primeiros anos de vida. Ainda, naquela que talvez seja a pedra de toque para um salto qualificado no patamar de relações sociais vigentes, é preciso resgatar o Estado das mãos dos setores abastados da população e promover a distribuição do poder de tomada de decisão aos cidadãos. Tal tarefa requer o estabelecimento de um sistema eficiente e de legítima representação popular de acompanhamento funcional das instâncias de funcionamento político e de gestão do espaço e bens públicos (o que inclui financiamento de campanhas eleitorais, processos licitatórios, empréstimos institucionais, transações de empresas públicas, elaboração, implementação e avaliação de políticas públicas).

Uma resposta possível ao sugerido papel do analista comportamental da cultura é, em sentido amplo, a promoção de estratégias de contracontrole social, o que pode fazer mediante a oferta dos recursos desenvolvidos por sua área de atuação a serviço do bem coletivo, norteado pelos eixos destacados e, acima de tudo, sensível às demandas coletivas levantadas pelas diferentes categorias de movimentos sociais civis organizados. Esforços precedentes que caminham na direção das questões apontadas por Biglan e por nós endossadas podem ser observados no desenvolvimento de guia e fluxograma como suporte para delineamentos culturais (Carrara et al. 2013), pautado na lógica da seleção por consequências como norte funcional para o delineamento de políticas públicas; em análise da viabilidade de estratégia comportamental de intervenção para controle da dengue (Carrara et al. 2012); em análises de legislação e atuação do poder público quanto à elaboração e cumprimento de leis (Lourencetti, 2015); em análises preliminares sobre os arranjos de contingências na condução das agências de controle educacional e governamental voltadas para ensino e pesquisa no país (Guazi \& Laurenti, 2015); em análise do funcionamento limitado de campanhas e programas governamentais de preservação de água (Perossi \& Carrara, 2012); em análise de contingências sociais relacionadas à gestão democrática da cidade e os mecanismos de participação popular em cidade do interior de São Paulo (Lourencetti, 2016); em análise de mecanismos de controle e contracontrole social, caracterizados pela atuação das agências de controle governamentais e os arranjos de contingências sociais por elas dispostos, bem como por seus efeitos nos cidadãos envolvidos nesse sistema social (Fernandes, 2016).

\section{CONSIDERAÇÕES FINAIS}

Diante dos dados e argumentos apresentados, parecenos possível concluir que a corrupção, tomada em suas dimensões comportamentais e, como tal, dotada de complexas dimensões históricas, econômicas e sociais, é suscetível a análises de relações funcionais e planejamentos de contingências sociais. Adicionalmente, depreende-se da análise até aqui desenvolvida que, teórica e tecnicamente, a corrupção como prática caracteriza-se por arranjos de esquemas de reforçamento complexos (em termos da configuração de contingências envolvidas) que implicam repertório comportamental de condenável ética - especialmente no âmbito da relação espúria com o poder público - e que tem permitido, nos tempos correntes, alcançar êxito na obtenção de reforçadores financeiros e outros a eles associados, por tempo indefinido e à custa de efeitos deletérios para a maior parte da população.

Decorrem do exposto ao menos três ênfases ou frentes de ação contra a corrupção que podem contar com a colaboração dos analistas do comportamento: (1) relacionada ao abandono à espécie de conviç̧ão vigente no senso comum, segundo a qual o corrupto, o corruptor e a própria corrupção constituem "coisas", eventos, estruturas, deformação de caráter, desvio ético-moral inato. O que este ensaio argumenta, evidentemente, é que a questão precisa ser tratada como resultante de um processo relacional, no qual o que predomina não é, em si, algo como uma personalidade má ou deformada, mas uma história de interações de indivíduos com o ambiente que pode ser mudada, a depender de novos rearranjos de contingências; 
(2) relacionada à ampla literatura já produzida no sentido de arranjar contingências para instalação e desenvolvimento de repertórios pró-sociais e pró-éticos desde a educação fundamental, por exemplo estabelecendo, mediante parâmetros transversais de ensino, regras compatíveis com contingências que preservem relações sociais justas, equitativas e contributivas para uma vida coletiva harmônica; (3) a importância do investimento, mediante políticas públicas de fomento à pesquisa, de recursos para o desenvolvimento de pesquisa e aplicação de achados sobre relações funcionais comportamento-ambiente que subsidiem consistentemente a formulação de um tratamento rigoroso e integrado com a contribuição dos movimentos sociais organizados, dos pesquisadores e da mídia.

Por fim, o que há, também na seara temática da corrupção, são contingências operando e modulando comportamentos indesejáveis. Mudá-las, sob os critérios e procedimentos da seleção pelas consequências, parece constituir, seguramente, uma contribuição relevante dos analistas do comportamento comprometidos com endossar os esforços da sociedade interessada em relações sociais justas e solidárias.

\section{REFERÊNCIAS}

Abramo, C. W. (2005) A dificuldade de medir a corrupção. Novos Estudos CEBRAP, 73, 33-37.

Ackerman, S. R. (1978). Corruption: A study in political economy. Nova Iorque: Academic Press.

Agbota, T. K., Sandaker, I., \& Ree, G. (2015). Verbal operants of corruption: A study of avoidance in corruption behavior. Behavior and Social Issues, 24, 141-163.

Araujo, V. M., Melo, C. M., \& Haydu, V. B. (2015). Código penal brasileiro como descrição de prática cultural: Uma análise comportamental de contingências e metacontingências. Revista Brasileira de Análise Do Comportamento, 11(2), 147-156.

Berninghaus, S. K., Haller, S., Krüger, T., Neumann, T., \& Schosser, S. (2013). Risk attitude, beliefs, and information in a Corruption Game - An experimental analysis. Journal of Economic Psychology, 34, 46-60.

Biglan, A. (2003). Selection by consequences: One unifying principle for a transdisciplinary science of prevention. Prevention Science, 4(4), 213-232.

Biglan, A. (2015). The Nurture Effect: How the science of human behavior can improve our lives and our world. Oakland: New Harbinger Publications.

Biglan, A. (2016). The need for a more effective science of cultural practices. The Behavior Analyst, 39(1), 97-107.

Bobkova, N., \& Egbert, H. (2013). Corruption investigated in the lab: A survey of the experimental literature. International Journal of Latest Trends in Finance and economic Sciences, 2(4), 337-349.

Bolsoni-Silva, A. T., Verdu, Carrara, K., A. C. M., Melchiori, L. E., Leite, L. P., Calais, S. L. (2013). Ampliando comportamentos pró-éticos dos alunos: Relato de pesquisa e intervenção com educadores do ensino fundamental. Temas em Psicologia, 21(2), 347-359.

Brasil. (1940). Decreto-Lei no 2848, de 7/12/1940. Código Penal. Rio de Janeiro, RJ. Recuperado de http://www.planalto.gov. br/ccivil 03/decreto-lei/Del2848.htm.

Cameron, L., Chaudhuri, A., Erkal, N., \& Gangadharan, L. (2008). Propensities to engage in and punish corrupt behavior: Experimental evidence from Australia, India, Indonesia and Singapore. Journal of Public Economics, 93(7-8), 843-851.

Carrara, K., \& Betetto, M. F. (2009) Formação ética para a cidadania: Uma investigação de habilidades sociais medidas pelo inventário de habilidades sociais. Estudos em Psicologia (Campinas), 26(3), 337-347.

Carrara, K., Souza, V. B., Oliveira, D. R., Orti, N. P., Lourencetti, L., Lopes, F. R., \& Bonaccorsi, C. (2012). Delineamentos culturais e politicas públicas: uma avaliação de estratégias comportamentais para o controle da dengue. Relatório de pesquisa (2012, CNPq), Departamento de Psicologia, Universidade Estadual Paulista, Bauru, São Paulo.

Carrara, K., Souza, V. B., Oliveira, D. R., Orti, N. P., Lourencetti, L., \& Lopes, F. R. (2013). Desenvolvimento de guia e fluxograma como suporte para delineamentos culturais. Acta Comportamentalia, 21(1), 99-119.

Carrara, K. (2015). Seleção pelas consequências como norte funcional para políticas públicas. In C. Laurenti \& C. E. Lopes (Orgs.), Cultura, democracia e ética: Reflexões comportamentalistas, (pp. 97-136). Maringá: EDUEM.

Controladoria-Geral da União. (2007). Convenção interamericana contra a corrupção. Brasília: CGU.

Cunha, A. G. (1982). Dicionário etimológico Nova Fronteira da língua portuguesa. Rio de Janeiro: Nova Fronteira.

Farias, E. (1962). Dicionário escolar latino-português. Rio de Janeiro: Ministério da Educação.

Fernandes, D. M. (2016). Governo, cultura e comportamento: Uma analise comportamental de agências de controle brasileiras. Projeto de Doutorado, Universidade Estadual Paulista Júlio de Mesquita Filho, Bauru, São Paulo.

Fernandes, D. M., Carrara, K., \& Zilio, D. (2017). Apontamentos para uma definição comportamentalista de cultura. Acta Comportamentalia, 25(2), 265-280.

Fernandes, D. M., Perallis, C. G., \& Pezzato, F. A. (2015). Creativity, brazilian "jeitinho", and cultural practices: A behavioral analysis. Behavior Analysis: Research and Practice, 15(1), 28-35.

Ferreira, A. B. H. (2004) Aurélio século XXI: O dicionário da Língua Portuguesa. Rio de Janeiro: Nova Fronteira.

Goldstein, M. K., \& Pennypacker, H. S. (1998). From candidate to criminal: The contingencies of corruption in elected public office. Behavior and Social Issues, 8(1), 1-8.

Guazi, T. S., \& Laurenti, C. (2015). Algumas contingências da produção acadêmica universitária: Um estudo preliminar. Psicologia: Ciência e Profissão, 35(1), 139-153.

Lamal, P., \& Greenspoon, J. (1992). Congressional metacontingencies. Behavior and Social Issues, 2(1), 71-81.

Lourencetti, L. A. (2015). Descrição e análise de contingências presentes em legislações referentes à mobilidade urbana. Dissertação de Mestrado, Universidade Estadual Paulista, Bauru, São Paulo.

Lourencetti, L. A. (2016). Políticas públicas de desenvolvimento urbano: Uma análise comportamental da gestão democrática 
da cidade. Projeto de Doutorado, Universidade Estadual Paulista, Bauru, São Paulo.

Maciel, F. G. (2005). O combate à corrupção no Brasil: Desafios e perspectivas. I Concurso de Monografias e Redações da Controladoria Geral da União - Brasil. Brasília, DF.

Mény, Y., \& de Sousa, L. (2001). Corruption: Political and public aspects. In N. Smelser \& P. B. Baltes (Eds.), International encyclopedia of the Social \& Behavioral Sciences (pp. 28242830). Exeter: Elsevier.

Pellegrini, L. (2011) Economic analysis of corruption. In Corruption, Development and the Environment (pp. 13-27). New York: Springer Science Business Media.

Perossi, G. R., \& Carrara, K. (2012). Por que funcionam limitadamente campanhas e programas de conservação de água? Uma análise comportamental. Interação em Psicologia, 16(2), 199-210

Santos. J. L. (2006). O que é cultura. São Paulo: Brasiliense. (Trabalho original publicado em 1983)

Shleifer, A., \& Visny, R. W. (1993). Corruption. Quarterly Journal of Economics, 108(3), 599-617.

Skinner, B. F. (1984). Contingências de reforço: Uma análise teórica. São Paulo: Abril Cultural. (Trabalho original publicado em1969)
Skinner, B. F. (1989). The origins of cognitive thought. American Psychologist, 44(1), 13-18.

Skinner, B. F. (2007) Seleção por consequências. Revista Brasileira de Terapia Comportamental e Cognitiva, 9(1), 129-137. (Trabalho original publicado em 1981)

Transparency International. (2014). Corruption perceptions index. Recuperado de http://www.transparency.org/cpi2014.

Transparency International. (2015). Corruption perceptions index. Recuperado de http://www.transparency.org/cpi2015.

Transparency International. (2017). Corruption perceptions index. Recuperado de https://www.transparency.org/news/feature/ corruption perceptions index 2017
Recebido em 07/05/2016

Revisado em 03/10/2016

Aceito em 05/12/2016 